\title{
A mixed-methods community-based participatory research to explore stakeholder's perspectives and to quantify the effect of crop residue burning on air and human health in Central India: study protocol
}

Tanwi Trushna', Vishal Diwan ${ }^{2,3^{*}}$ D, Subroto Shambhu Nandi ${ }^{4}$, Satish Bhagwatrao Aher ${ }^{4}$, Rajnarayan R. Tiwari ${ }^{5}$ and Yogesh Damodar Sabde ${ }^{1}$

\begin{abstract}
Background: Crop residue burning adversely affects air quality and consequently human health. India, being one of the largest agro-economies of the world, produces around 500 Million tonnes of crop residue annually most of which is burnt on-farm. However, integrated studies that simultaneously quantify the effects of crop residue burning while exploring the subjective determinants of the practice are lacking in India. This paper describes the protocol for a longitudinal mixed methods research study employing a community-based participatory approach to fill this gap.

Methods: Both quantitative and qualitative data will be collected in a rural setting of the central Indian province of Madhya Pradesh, over 1 year. A steering committee comprising of the research team and community representatives will be formed. The proportion of cultivable land burnt in one crop burning season will be estimated. The association between crop residue burning, level of ambient air pollutants, and pulmonary function of village residents will be determined. Focus groups, interviews, and participatory rural appraisal methods will be used to explore stakeholder perspectives about crop residue burning. Potential barriers and opportunities for substituting burning with an alternative crop residue management technique will be ascertained as the basis for future interventions. Ethics approval has been obtained from the Institutional Ethics Committee of the National Institute for Research in Environmental Health (No: NIREH/BPL/IEC/2019-20/1494, dt 06/01/2020).

(Continued on next page)
\end{abstract}

\footnotetext{
* Correspondence: vishaldiwan@hotmail.com

${ }^{2}$ Department of Environmental Monitoring And Exposure Assessment (Water

and Soil), ICMR-National Institute for Research in Environmental Health,

Bhopal, Madhya Pradesh, India

${ }^{3}$ Department of Global Public Health, Karolinska Institutet, Stockholm,

Sweden

Full list of author information is available at the end of the article
}

(c) The Author(s). 2020 Open Access This article is licensed under a Creative Commons Attribution 4.0 International License, which permits use, sharing, adaptation, distribution and reproduction in any medium or format, as long as you give appropriate credit to the original author(s) and the source, provide a link to the Creative Commons licence, and indicate if changes were made. The images or other third party material in this article are included in the article's Creative Commons licence, unless indicated otherwise in a credit line to the material. If material is not included in the article's Creative Commons licence and your intended use is not permitted by statutory regulation or exceeds the permitted use, you will need to obtain permission directly from the copyright holder. To view a copy of this licence, visit http://creativecommons.org/licenses/by/4.0/ The Creative Commons Public Domain Dedication waiver (http://creativecommons.org/publicdomain/zero/1.0/) applies to the data made available in this article, unless otherwise stated in a credit line to the data. 
(Continued from previous page)

Discussion: This manuscript describes the protocol for a novel community-based participatory study to investigate thoroughly the phenomenon of crop residue burning from the perspective of the agricultural community through their active collaboration. The lack of comprehensive evidence regarding the factors responsible for crop residue burning in India underlines the importance of implementing this study protocol to fill in this critical gap in knowledge. While acknowledging that findings of this study will be not generalizable to agricultural communities other than the one studied, it is expected that the study will generate baseline evidence that might be beneficial in developing and implementing an appropriate intervention strategy.

Keywords: Air pollution, Crop residue burning, Community-based participatory research, Focus groups, Key informant interview, India

\section{Background}

Ambient air pollution (AAP) has emerged as one of the major threats to public health worldwide [1]. According to statistics reported by the World Health Organisation (WHO) in 2018, 4.2 million annual premature deaths occur as a consequence of exposure to AAP [2]. Research has highlighted that exposure to AAP above permissible levels increases morbidity and mortality in humans $[3,4]$. Life-long exposure to AAP is the fifth largest risk factor for all-cause mortality and results in a loss of $4.2 \%$ of global disability-adjusted life years (DALYs) [5]. Inhalation of ambient air pollutants has been associated with a wide range of morbidities ranging from cardiovascular and respiratory diseases $[6,7]$ which together account for almost $80 \%$ of the global life expectancy loss attributable to air pollution [4] to endocrine [8,9] and even neuropsychiatric dysfunction [10-12].

Multiple studies have highlighted the adverse impact of agricultural emissions on air quality [13-18]. Burning of crop residues is an important source of agricultural emissions [19] which endangers the environment because of the generation of greenhouse gases and particulate emissions [20-22]. The deliberate use of fire in agriculture is dwindling worldwide but CRB is being increasingly practised in India [23, 24]. India is one of the largest agro-economies of the world [25] and it produces around 500 Million tonnes of crop residue annually [20] most of which is burnt on-farm. According to a recent study, in 2017 CRB resulted in annual emissions of 824 $\mathrm{Gg}$ of Particulate Matter $\left(\mathrm{PM}_{2.5}\right), 58 \mathrm{Gg}$ of Elemental Carbon, $239 \mathrm{Gg}$ of Organic Carbon, and $211 \mathrm{Tg}$ of greenhouse gases [26]. The authors also predicted that emissions from CRB will increase by $45 \%$ in 2050 as compared to 2017 [26].

The negative impact of CRB induced air pollution on human health has been documented by previous research $[27,28]$. CRB induces or exacerbates asthma attack [29] and pulmonary function compromise was found to persist even after cessation of burning [30]. Living in areas with high-intensity CRB raises the risk of acute respiratory infection by three times and the danger is most severe in children [31]. Previous studies have demonstrated the presence of carcinogenic benzenoids and other harmful chemicals in emission from CRB [32-34]. Every burning season the number of patients visiting local hospitals in the north Indian province of Punjab rises by almost $10 \%$ [35] and a corresponding increase in average household healthcare expenditure has also been documented [36]. Eliminating emissions from agricultural activities can avert nearly one-fifth of $\mathrm{PM}_{2.5}$ related deaths on a global scale [18] and will, therefore, facilitate the achievement of the sustainable development goal (SDG) of substantially reducing mortality and morbidity caused by air, water, and soil pollution by the year 2030[target 3.9 [37]].

The overall public acceptance of government-initiated interventions to contain CRB in India in form of legal enforcement, monetary incentives, as well as penalties, has been poor $[38,39]$ which is a testament to the complexity of the issue. Even though tackling such a complex issue requires an in-depth understanding of the phenomenon, no research to date has attempted to provide a comprehensive overview of $\mathrm{CRB}$ encompassing both quantitative inventories of the effects of CRB as well as an in-depth understanding of the subjective determinants of the practice.

This manuscript thus describes the protocol for an exploratory study to be conducted through the active collaboration of the rural agricultural community in Madhya Pradesh, a province in Central India to collect baseline information using mixed-method approaches. Based on this information, a suitable intervention will be planned and implemented in the subsequent phases to promote the adoption of alternative crop residue management techniques. Specifically, it aims to achieve the following objectives:

\section{Sub-study 1}

1. To estimate using Geographic Information System the proportion of cultivable areas where wheat crop residues are burnt. 
2. To evaluate the association between crop residue burning and the concentration of ambient air pollutants.

3. To identify the impact of crop residue burning on the pulmonary function of village residents.

\section{Sub-study 2}

1. To explore the perspective of stakeholders about the effect of crop residue burning on the environment and human health and adoption of potential alternatives.

2. To determine barriers and opportunities for the adoption of alternative crop residue management techniques to identify a suitable intervention for reducing $\mathrm{CRB}$.

\section{Methods}

\section{Design}

This is the protocol for a mixed methods research study that aims to employ a community-based participatory approach to ascertain objective achievement. This study will be conducted over 1 year. The time schedule of various study methods of this protocol is described in Fig. 1.

\section{Setting}

This study will be conducted in one administrative subdivision (Shyampur) of Sehore District in the central Indian province of Madhya Pradesh (MP) (Fig. 2).MP has a population of almost 72 million [40], of which almost $75 \%$ reside in rural areas and depend on agriculture for their livelihood [41]. Over the last few years, the agricultural growth rate has drastically increased in MP [42]. Thus huge amounts of crop residues (33.18 Million tonnes/year) are being generated and burnt in this province [43]. The predominant cropping pattern in this province involves wheat-soyabean crop rotation [43].

Sehore district consists of eight tehsils (administrative subdivision)covering1031 villages with a total population of 1.3 million [44]. Using the latest national census data [45], we compiled a list of villages of the district in which at least $50 \%$ of the total population is involved in agriculture and at least $50 \%$ of the total geographic area is used for cultivation. From this list, the village with the largest population and the highest proportion of land under agriculture will be chosen.

\section{Formation of steering committee}

Previous studies adopting a community based participatory approach have engaged their target communities more efficiently through the creation of steering committees comprising of community and academic partners [46-48]. Thus, in the current study, we too will attempt to enhance community participation in research by forming a steering committee consisting of research, technical and community members. The community members of the steering committee who represent the community will act as a bridge for proper communication between researchers and the village community and will help foster a rapport between them.

The committee members will collect sociodemographic and economic information of all village household members for line listing. The steering committee will be involved in planning, feedback, trouble-shooting,

\begin{tabular}{|c|c|c|c|c|c|c|c|c|c|c|c|c|c|}
\hline S.N. & Methods & 1 & 2 & 3 & 4 & 5 & 6 & 7 & 8 & 9 & 10 & 11 & 12 \\
\hline 1 & Steering committee & & & & & & & & & & & & \\
\hline 2 & GIS & & & & & & & & & & & & \\
\hline 3 & PFT & & & & & & & & & & & & \\
\hline 4 & Air Quality & & & & & & & & & & & & \\
\hline 5 & $\begin{array}{l}\text { PRA } \\
\end{array}$ & & & & & & & & & & & & \\
\hline 6 & FGD & & & & & & & & & & & & \\
\hline 7 & KII & & & & & & & & & & & & \\
\hline 8 & KAP & & & & & & & & & & & & \\
\hline 9 & Data Analysis & & & & & & & & & & & & \\
\hline 10 & Dissemination & & & & & & & & & & & & \\
\hline
\end{tabular}

Fig. 1 Time Schedule of study methods. Note: The numbered columns represent duration in months (the period of crop residue burning is highlighted in red colour). Abbreviations: FGD: Focus Group Discussion; GIS: Geographic Information system; KAP: Knowledge Attitude Practice; KII: Key Informant Interview; PFT: Pulmonary Function Test; PRA: Participatory Rural Appraisal 

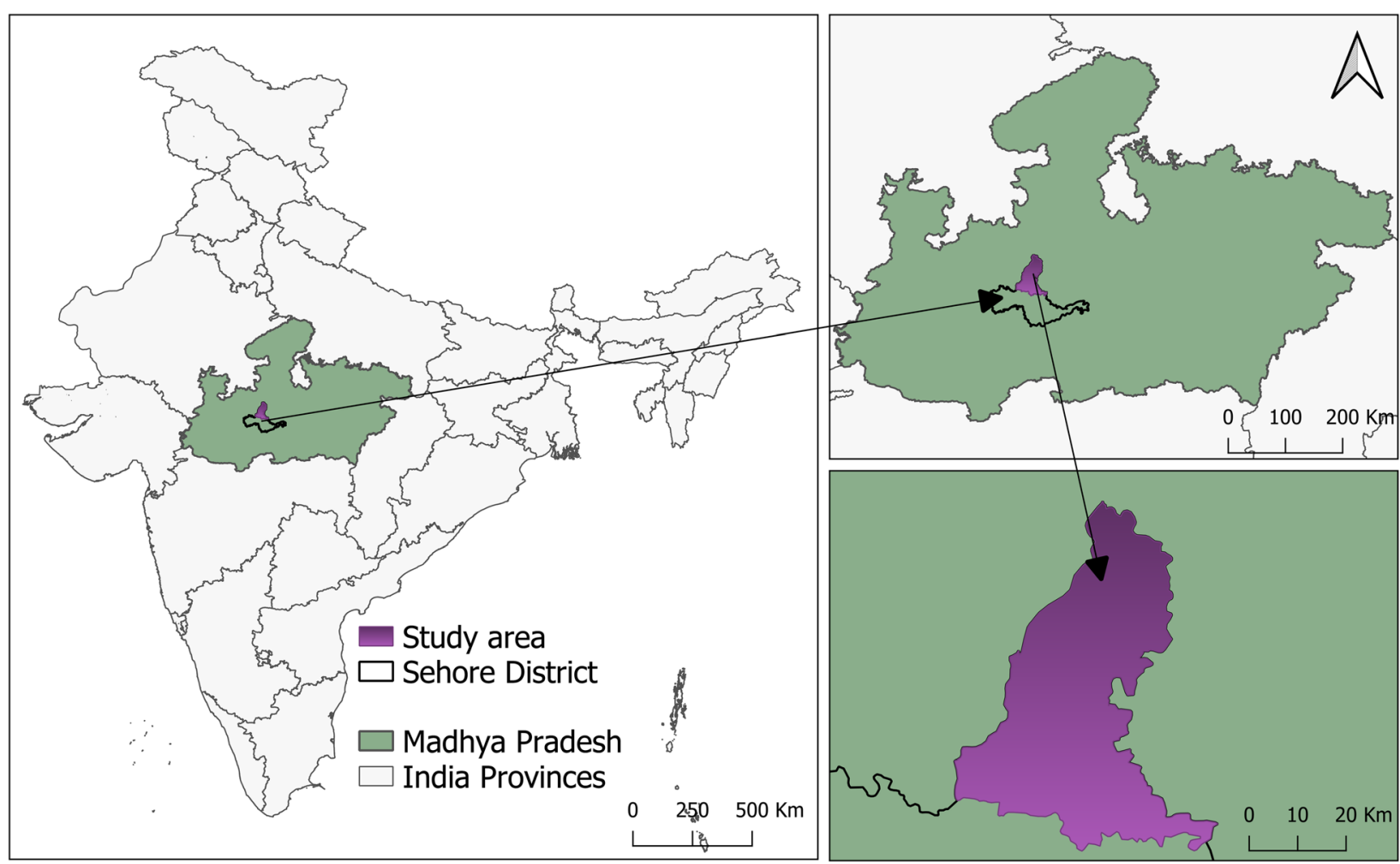

Fig. 2 Geographical location of the selected study area. Note: The map shows clockwise, India, Madhya Pradesh, and Sehore District respectively. The village where the study will be conducted will be selected from among the villages of Sehore District. (The map in this figure was created by the authors for use in this manuscript)

and executing the entire study (for example organization of village meetings, participant selection, etc.). They will also be in charge of disseminating the study results to the village community. Committee meetings will be held fortnightly to monitor progress and regularly solve operational issues.

For the selection of community representatives, a village meeting organized will be held on a pre-advertised date. Nominations will be sought for five or more representatives who are knowledgeable about and respected in the community. Community members of the steering committee will represent different socioeconomic classes and will be of both genders.

\section{Participants and Methods \\ Sub-study 1}

Objective 1 To estimate using Geographic Information System (GIS) the proportion of cultivable areas where wheat crop residues are burnt.

Method The burden of CRB will be estimated through the calculation of the proportion of total area under cultivation which is burnt during the study period within the administrative boundary of the selected village using the Geographic information system (GIS) and physical field survey. For this, the hard copy of the village administrative boundary maps will be retrieved. These maps will be scanned and registered in the relevant coordinate system for digitization in a vector file using ArcMap 10.7.1. Information regarding burning will be collected by members of the steering committee. The boundaries of farms where crop residues have been burnt as well as the ones where no burning has been done within the administrative limit of the selected village will be plotted as polygons using handheld global positioning system (GPS) survey equipment (GARMIN GPSMAP 64). The data collected will then be exported to GIS as described above for subsequent calculation and data analysis.

Objective 2 To evaluate the association between crop residue burning and the concentration of ambient air pollutants.

Method The ambient air quality concerning the key air pollutants viz., $\mathrm{PM}_{10}, \mathrm{PM}_{2.5}, \mathrm{NO}_{\mathrm{x}}$, and $\mathrm{SO}_{2}$ in the vicinity of the identified site will be monitored for 1 year using a respirable dust sampler (RDS)/high volume air sampler (HVAS) placed $3 \mathrm{~m}$ above ground in ambient air. The monitoring will be carried out twice a week for 
$24 \mathrm{~h}$. The sampling time of $4 \mathrm{~h}$ and $8 \mathrm{~h}$ for particulate pollutant and gaseous pollutants, respectively will be followed as per Ambient Air Quality Monitoring Guidelines issued by the Central Pollution Control Board [49]. $\mathrm{PM}_{10}$ and $\mathrm{PM}_{2.5}$ samples will be collected over previously dried and weighed glass microfibre filters (Whatman GF/A) by drawing the air at a flow rate of 1.1 to $1.2 \mathrm{~m}^{3}$ per minute for $8 \mathrm{~h}$. The concentration of particles will be calculated gravimetrically as per standard methods [49].

The presence of $\mathrm{SO}_{2}$ in ambient air will be detected by absorbing a calculated volume of air into potassium tetrachloromercurate solution which will result in the formation of a stable dichlorosulphitomercurate complex. There afterward, para rosaniline and methyl sulphonic acid will be added and the absorbance of the coloured solution will be detected at $530 \mathrm{~nm}$ through the use of a spectrophotometer. Modified West \&Gaekemethod will be utilised to calculate the concentration of sulphate ions $[49,50]$. Similarly, to measure ambient air $\mathrm{NO}_{2}$ a calculated volume of air is passed through sodium hydroxide and sodium arsenite solution. Nitrite ions produced through this process will be determined calorimetrically. Phosphoric acid, sulphanilamide, and $\mathrm{N}$-(1-naphthyl)-ethylenediamine di-hydrochloride will be added to the solution and the absorbance of the coloured azo-dye thus produced will be measured at $540 \mathrm{~nm}[49,51,52]$.

Objective 3 To identify the impact of crop residue burning on the pulmonary function of village residents.

Participants Healthy [non-smoker; no recent (within previous 1 month) history of myocardial infarction, aneurysm, surgery; no active diseases (e.g. pulmonary Tuberculosis, active haemoptysis, orofacial pain, acute respiratory infection, etc.); no pregnancy] adults $(\geq 18$ years of age) and adolescents ( 6 to $<18$ years of age) of both genders.

Method The number of participants to be sampled was calculated using the nMaster 2.0 software based on the differences in lung function (Forced vital capacity) before and after wheat crop residue burning as previously reported by a study conducted in Punjab, India by Awasthi et al., 2010 [53]. A sample size of 105 participants provides a $90 \%$ power to detect a measurable difference in lung function before and after exposure to CRB with a two-sided type I error of $5 \%$, assuming that the non-responder rate will be $10 \%$. Thus pulmonary function testing will be done in 105 adults and 105 children.

Systematic random sampling will be used for the selection of participants. From a list of all village households,
105 households will be randomly chosen. From the selected households, one eligible adult and one child participant of either gender will be selected. If there are $>1$ eligible participants in the household, then one will be selected using the Troldahl-Carter-Bryant Respondent Selection Method [54] (Table 1).

Pulmonary function test (PFT) will be done monthlyonce before, during (roughly 3 months- three times), and once after the last field is burnt. The age, height, and weight of all participants will be recorded on the first contact. Each participant will be asked to fill a questionnaire to elicit data regarding other risk factors that can affect PFT such as occupational details, medical history, etc. The investigation will be conducted using a portable spirometer (EasyOne Model no. 2001) on comfortably seated participants.

PFT parameters like forced expiratory volume in 1st second $\left(\mathrm{FEV}_{1}\right)$, forced vital capacity (FVC), and peak expiratory flow (PEF) will be assessed through spirometry administered by a trained technician, supervised by a trained physician, following national guidelines for spirometry [55]. At least three acceptable spirograms will be obtained such that the two largest FVC measurements and the two largest FEV1 measurements vary by $\leq 0.150$ l. Testing will be repeated either until the criteria are fulfilled or until the test has been performed eight times. The entire procedure will require around $20-30 \mathrm{~min}$. The best measurement for each parameter will be recorded for each participant.

\section{Sub-study 2}

Objective 1 To explore the perspective of stakeholders about the effect of crop residue burning on the environment and human health and the adoption of potential alternatives.

Objective 2 To determine barriers and opportunities for the adoption of alternative crop residue management techniques to identify a suitable intervention for reducing CRB.

Table 1 Schema for the selection of eligible individual from the household

\begin{tabular}{|c|c|c|c|c|}
\hline \multirow{2}{*}{$\begin{array}{l}\text { Number of adult/ } \\
\text { child females in } \\
\text { the household }\end{array}$} & \multicolumn{4}{|c|}{ Number of adults/children in the household } \\
\hline & 1 & 2 & 3 & 4 or more \\
\hline 0 & Male & $\begin{array}{l}\text { Youngest } \\
\text { Male }\end{array}$ & $\begin{array}{l}\text { Youngest } \\
\text { Male }\end{array}$ & Oldest Male \\
\hline 1 & Female & Female & Oldest Male & Female \\
\hline 2 & & $\begin{array}{l}\text { Oldest } \\
\text { Female }\end{array}$ & Male & Oldest Male \\
\hline 3 & & & $\begin{array}{l}\text { Youngest } \\
\text { Female }\end{array}$ & Oldest Male \\
\hline
\end{tabular}


Table 2 Details of PRA tools to be used, participants and data to collected using them

\begin{tabular}{lll}
\hline Tool & Information to be collected using it & Participant groups \\
\hline Objective 1 of sub-study 2: &
\end{tabular}

\section{Qualitative Research Methods:}

FGD

KII

Seasonal Analysis [57]

Scoring Method [58]

Objective 2 of sub-study2:

PRA tools:

Trend Analysis [56]
To explore participants' views regarding CRB, its adverse consequences, and their reasons for continuing CRB.

To elicit stakeholders' perspectives about CRB and its effects specific to their area of expertise (for example, local health care providers will be asked to describe effects of CRB on the health profile of village residents, etc.)

Qualitative Research Methods:

KII

\section{PRA tools:}

Resource Mapping [57]

Social Mapping [57]

Wealth Ranking [58] management practices adopted by the villagers with a special focus on CRB and to generate discussions health status of villagers and the onset of CRB.

To explore the association of perceived air quality and health concerns with CRB season

To understand the community's perception regarding air quality concerns (including (RB) and related health consequences in the village
To understand the historical chronology of crop residue regarding any perceived association between the perceived barriers to adopting an alternative crop residue management practice and their level of interest in supporting or opposing an intervention aimed at changing the current crop residue management practice.

To discuss their perspectives about potential barriers and opportunities along with their level of interest in supporting the implementation of an intervention aimed at promoting the adoption of healthy crop residue management techniques.
Village residents

Stakeholders indirectly involved with CRB
Adults with chronic respiratory diseases, Mothers with young children, Health care workers residing in the village.

Male and female adults according to residential proximity to farmland

Village residents

Stakeholders indirectly involved with CRB
Village leaders, self-help groups e.g. agriculture groups can influence the planning of an alternative crop residue management practice. For example, participants will be asked to depict the way their village looks like while focussing on the various resources pertinent to farming such as the spatial distribution of farmlands, water reservoirs, storage spaces, dairy farms (if any), etc.

To explore the habitation pattern in the village especially concerning the farms to understand the probable effect of CRB on human health

To understand the social infrastructure and the inherent hierarchy in the village community which can have a bearing on the individual decision-making process of the villagers and thus on the acceptance of an intervention

To understand the local perceptions regarding wealth distribution in the village and thus the economic hierarchy in the village community which can have a bearing on the individual decision-making process of the villagers and thus on the acceptance of an intervention
Male and female representatives from different social categories e.g. castes

Male and female representatives from different socioeconomic categories e.g. landowners vs landless labourers 
The aforementioned objectives will be achieved through qualitative research methods enlisted below (Details in Table 2):

\section{Participatory rural appraisal}

Participants Village community members.

Method Participants will be selected through purposive sampling by community members of the steering committee utilizing their "insider" knowledge of the community. A combination of six PRA tools, namely resource mapping, social mapping, wealth ranking, trend analysis, seasonal analysis, and scoring method will be used to understand the community's perception of CRB, its effect on the environment and human health, and to explore potential barriers and opportunities to the adoption of alternative crop residue management techniques (Table 2).

Village meetings will be organized and PRA activities will be held as per standard guidelines [59]. Moderator will facilitate the process and the note-taker will actively take notes. Participants will be asked to pictorially depict their perspectives for mapping activities and to provide relative ranks and scores for the rest methods. Researchers will probe to clarify aspects that are not clear. Local materials such as stones, leaves, trees sticks, etc. will be were used in addition to flip charts, marker pens, maps, GPS. At the end of the activity, the depicted maps will be saved (either copied onto papers or photographs of for maps created on ground capture using cameras) for analysis.

\section{Focus Group Discussion}

Participants Village residents.

Methods Participants will be selected through a purposeful sampling method with maximum variation in age, gender, and land ownership and FGDs will be continued until saturation is attained [60,61]. Using a semistructured topic guide (Appendix 1 in Supplementary Material), researchers will attempt to elicit participants' views regarding $C R B$, its adverse consequences, and their reasons for continuing CRB. Their opinion and concerns/ perceived barriers to adopting an alternative crop residue management practice will also be explored. We will further explore the participants' level of interest in supporting or opposing an intervention aimed at changing the current crop residue management practice. The resources at their disposal, their alliances, and their level of influence on the village community will also be discussed.

\section{Key Informant Interview:}

Participants Stakeholders indirectly involved with CRB such as local health care providers, agriculture extension workers, employees of government and non-government organizations, local political leaders, etc.

Methods Participant selection will be done through purposive sampling and interviews will be continued until saturation is attained [60,61]. Participants' perspectives about CRB and its effects specific to their area of expertise (for example, local health care providers will be asked to describe effects of CRB on the health profile of village residents, etc.) will be elicited using a topic guide (Appendix 2 in Supplementary Material). Their perspectives about potential barriers and opportunities along with their level of interest in supporting the implementation of an intervention aimed at promoting the adoption of healthy crop residue management techniques will also be discussed.

The discussion and interviews will be conducted in the local language (Hindi) by research staff trained in qualitative data collection methods [62,63]. The duration of each discussion/interview will be approximately 60-90 min. Audio-recording will be done and field notes will be taken.

\section{Quality control}

Various control measures will be adopted to ensure the collection of high-quality data. Necessary training will be research staff. Quantitative and qualitative data collection tools will be validated before use. A pilot study in a nearby rural setting will be conducted to field test the study methodology, data collection instruments and to train the research assistants. Similarly, the quality of air pollutant concentration estimation will be ensured through meticulous checking of filter papers, sampling equipment, and reagents to be used.

\section{Data management}

The investigator assigned the responsibility of data management will ensure that the data is stored safely and timely back-ups are maintained.

\section{Quantitative Data management}

Filled questionnaires and samples will be assigned unique identifiers. Data from questionnaires and those generated during the analysis of laboratory samples will be entered into the latest version of Microsoft Excel spreadsheets. Data from all sub-studies will be linked. Senior researchers will supervise data entry and doublecheck at least $10 \%$ of the entered data for quality assurance. Post data entry, hard copies of questionnaires will be stored in a secure archive in the institute. All 
computer-based data kept under password protection will be handled by research staff alone.

\section{Qualitative Data management}

Hard copies of maps and ranking charts generated during PRA activities will be converted into soft copies containing relevant identifying details such as date, title, and purpose of the exercise. These hard copies along with the field notes of FGDs and KIIs will be stored in a secure archive in the institute whereas soft copies and audio-recordings will be stored confidentially in password-protected computers.

\section{Data analysis}

\section{Data analysis of quantitative data (sub-study 1)}

Analysis of the data will be done using SPSS statistics software (Version 26). Descriptive statistics like mean, median, standard deviation, 95\% confidence interval, interquartile range, and percentages/proportion will be used. The total cultivable area and the area where crop residues are burnt in the village will be calculated using the area calculator tool of ArcMap (10.7.1). The proportion of area burnt out of the total cultivable area will then be estimated. The timing and proportion of cultivable area burnt will then be correlated with the trend of change in the concentration of air pollutants recorded, The mean change in the PFT parameters of the villagers before, during, and after CRB will be calculated. ANOVA repeated measures will be used to check for any significant change in the PFT parameters across different time points. Multiple linear regression analysis will be used to detect the independent effect of CRB on PFT parameters while adjusting for known confounders.

\section{Data analysis of qualitative data (sub-study 2)}

Audio-recording and field notes will be used to create transcripts and translation of those into English.
Thematic analysis approach using the Framework Method [64] will be used to analyse the data collected. Data coding and analysis will be done by two researchers separately (TT and VD) and interpretations will then be compared. In the case of conflict, the resolution will be done through a consensus reached by all committee members.

Stakeholder mapping: Based on the themes generated from analysis and the information obtained during social mapping \& wealth ranking, stakeholder mapping will be done following the Power-interest grid as shown in Fig. 3 [65]. The presence of influence directions and the strength of influence will also be noted wherever possible.

\section{Dissemination}

Dissemination of the study findings will be done in two stages. In the first stage, with the help of the community members of the steering committee, village meetings will be organised to inform the participating community regarding the conclusions drawn. After appropriate discussion with the community, in the second stage, dissemination will be done in scientific forums through publications.

\section{Ethical considerations}

Ethics approval has been obtained from the Institutional (Human) Ethics Committee, National Institute for Research in Environmental Health (No: NIREH/BPL/IEC/ 2019-20/1494, dt 06/01/2020). Before the initiation of research activities, the community of the selected village will be approached starting with the gatekeepers (village leaders) whose consent will be solicited for the creation of the steering committee.

Before the onset of data collection, each participant (guardians for PFT participants $<18$ years of age) will be provided detailed oral and written information in Hindi

\begin{tabular}{|c|c|}
\hline $\begin{array}{l}\text { High Influence }+ \text { Low Interest } \\
\text { (Currently, Pre-intenders with potential } \\
\text { to become either Intenders or Blocker) } \\
\text { Avoid overwhelming } \rightarrow \text { Engage \& consult } \\
\text { in interest areas } \rightarrow \text { Efforts to increase } \\
\text { positive interest }\end{array}$ & $\begin{array}{l}\text { High Influence }+ \text { High Interest } \\
\text { (Key Players- High Potential to become } \\
\text { Actors + create more Actors) } \\
\text { Actively engage and consult regularly } \rightarrow \\
\text { Maximum effort for Behaviour change }\end{array}$ \\
\hline $\begin{array}{l}\text { Low Influence + Low Interest } \\
\text { (Pre-intenders, Low potential to become } \\
\text { Blocker) } \\
\text { Keep informed but expend minimum } \\
\text { effort. }\end{array}$ & $\begin{array}{l}\text { Low Influence }+ \text { Low Interest } \\
\text { (Potential to become Actors but cannot } \\
\text { create more actors) } \\
\text { Utilise Interest by engaging and consulting } \\
\text { whenever possible } \rightarrow \text { Efforts to change } \\
\text { behaviour as per available resources. }\end{array}$ \\
\hline
\end{tabular}

Fig. 3 Influence-Interest Grid. Note: Influence is plotted on the vertical axis and Interest on the horizontal axis. According to the details plotted on this grid, a stakeholder management plan will be devised for behaviour change intervention in the next phase of the study 
(local language) and English regarding the aim and procedure of study in an easy to understand manner and all queries will be answered. After reiterating the fact that participation is voluntary and that the information shared will be kept confidential, participants will be asked to sign the consent form (Appendix 3,4 in Supplementary material). In case the participant is below 18 years of age, parental/guardian written consent will be obtained along with assent from the child (Appendix 5 in Supplementary material). In addition, permission for audio-recording of interviews and focus group discussions will be obtained. Necessary precautions (e.g. use of disposable mouthpieces) for prevention of the spread of airborne infections will be applied while performing spirometry. In case of any discomfort experienced by the participants during the procedure, doctors in the research team will assess the participant and will refer those requiring medical attention to the nearest healthcare facility.

\section{Discussion}

This protocol describes a mixed-methods research study that will be conducted in the rural setting of the central Indian province of Madhya Pradesh to study the diverse and complex problem of CRB. The burden of CRB in terms of the proportion of cultivable areas where wheat crop residues are burnt will be estimated using field surveys, GPS, and GIS. Many previous studies have employed GIS in conjunction with satellite data to estimate the CRB burden $[66,67]$. However, in the current study protocol CRB burden will be estimated for one village and thus can be easily done even without the use of remote sensing data.

Previous studies in India have documented the emission of air pollutants owing to CRB $[68,69]$ and the consequent effect on the pulmonary health of exposed individuals [31, 70]. However, most of these previous studies have mostly focussed on the northern parts of India especially Punjab and Haryana. The current study protocol aims to document the effect of CRB on air quality and human health in Madhya Pradesh, a province in central India. Over the last few years, a drastic increase has been noted in the agricultural growth rate in MP leading to higher production of grains and thus residues [71]. As a result, CRB is no longer restricted to the traditional pre-winter burning of paddy residues in northern India and instead has spread to MP as well [72-74]. Nevertheless, not many studies have documented the extent and effect of CRB in MP. The current protocol when implemented will fill this critical gap in information.

Few studies have attempted to scientifically explore the reasons behind the widespread persistent acceptance of $\mathrm{CRB}$ by farmers in India despite contrary legal enforcement [75-79]. But even those studies have mostly used structured questionnaires to quantitatively compile the reasons [76-78] and only a couple of studies have qualitatively explored farmers' perspectives $[75,79]$. A mixed-methods approach will thus be adopted in the current study to overcome this lacuna.

CRB is a multidimensional issue since it affects and is in turn affected by other critical sustainability issues confronting agriculture such as groundwater depletion and thus the generation of a solution requires multidisciplinary research focussing on the multitude of related aspects of CRB [80]. Therefore, the current protocol thus chooses to focus on multiple objectives with an overarching goal to document baseline evidence to assist in the development of a suitable intervention designed to promote the adoption of an alternative crop residue management technique. Interventions to curb CRB have not been initiated in MP and even those that have been implemented elsewhere have not been widely successful [38, 39]. In this context, it is important to note that CRB, although harmful to the environment in large $[68,69]$, does not produce immediate clinically apparent individual-level adverse health effects and instead is inexpensive [81] and even appears to increase the yields of next sown crop [82]. Thus, it is a behaviour widely adopted by farmers $[81,83]$. To promote an alternative to such an ingrained and apparently beneficial behaviour, the implemented intervention will need to overcome the inertia and hesitation to change [84]. Research has highlighted the role played by theorydriven behaviour change interventions in promoting sustainable pro-environment change $[85,86]$. The baseline data collected through the current study will thus enable planning, implementation, and evaluation of an appropriate intervention to curb CRB in MP.

Public acceptance of any intervention is crucial to its success [87]. The benefits of using a community-based participatory approach in this context are gradually being recognised in public health research since it increases collaboration between academia and the community [88, 89]. Partnering with the stakeholder community allows for the research findings to be grounded in the context, enriched by diverse perspectives and expertise, and therefore more appropriate and acceptable to the community [90]. Thus the current study protocol, through the formation of a steering committee consisting of community representatives as members will attempt to ensure collaboration and foster mutual trust and rapport which in turn will facilitate our understanding of the hitherto unexplored perspectives of stakeholders. The use of participatory techniques such as PRA and focus groups will empower the community members to actively engage in discussing problems as well as identifying appropriate and acceptable solutions $[91,92]$. 


\section{Methodological considerations}

To the best of our knowledge, the current study is the first to employ a participatory approach to collaborate with the agricultural community in analysing the extent and effect of CRB. The juxtaposition of qualitative and quantitative research methods for data collection in the current study will yield comprehensive information regarding CRB and this will be actualised through a multidisciplinary research team that constitutes a potential strength of this study. Furthermore, the use of varied participant groups, multiple data sources, and collection methods, as well as several researchers in a study, through a data source, method, and investigator triangulation [93], will augment the credibility and validity of the study results.

This study protocol will be implemented in a limited geographical area and the findings of this study will be specific to the studied population. Thus insights generated cannot be accurately extrapolated to diverse populations. However, lessons learnt during this study will aid the conduct of similar research in other communities. Furthermore, no control group will be included in this study which reduces our ability to compare and derive accurate conclusions regarding the effect of CRB on air quality. Despite the fact that participants will simultaneously be exposed to pollutants in their home environment, we will not be able to monitor and measure indoor air pollution.

\section{Conclusion}

This manuscript describes the protocol for a novel community-based participatory study to investigate thoroughly the phenomenon of CRB from the perspective of the agricultural community through their active collaboration. The lack of comprehensive evidence regarding the factors responsible for CRB, especially in MP underlines the importance of implementing this study protocol to fill in this critical gap in knowledge. While acknowledging that findings of this study will be not generalizable to agricultural communities other than the one studied, it is expected that the study will generate baseline evidence that might be beneficial in developing and implementing an appropriate intervention strategy to mitigate $\mathrm{CRB}$ in MP.

\section{Supplementary Information}

The online version contains supplementary material available at https://doi. org/10.1186/s12889-020-09844-6.

Additional file 1. Supplementary Material Appendix 1. Focus Group Discussion (FGD) Tentative Topic Guide- Village Residents. Appendix 2. Key Informant Interview (KII) Tentative Topic Guide- Stakeholders.

Appendix 3. Patient Information Sheet and Consent form- Qualitative data collection. Appendix 4. Patient Information Sheet and Consent form- PFT (adults). Appendix 5. Patient Information Sheet, Parental Consent and Child Assent form- PFT (Child).

\section{Abbreviations}

AAP: Ambient air pollution; CRB: Crop residue burning; DALY: Disabilityadjusted life years; FEV 1 : Forced expiratory volume in 1st second; FGD: Focus Group Discussion; FVC: Forced vital capacity; GIS: Geographic Information system; HVAS: High volume air sampler; KAP: Knowledge Attitude Practice; KIl: Key Informant Interview; MP: Madhya Pradesh; $\mathrm{NO}_{x}$ : Nitrogen oxides; PEF: Peak expiratory flow; PFT: Pulmonary Function Test; PRA: Participatory Rural Appraisal; $\mathrm{PM}_{10}$ : Particulate matter with aerodynamic diameter $<10 \mu \mathrm{m}$; $\mathrm{PM}_{2.5}$ : Particulate matter with aerodynamic diameter $<2.5 \mu \mathrm{m}$; RDS: Respirable dust sampler; $\mathrm{SO}_{2}$ : Sulphur dioxide; SDG: Sustainable Development Goal; WHO: World Health Organisation; m: Metre; $\mathrm{cm}$ : Centimetre $\left(1 \mathrm{~cm}=10^{-2} \mathrm{~m}\right)$; $\mathrm{mm}$ : Millimetre $\left(1 \mathrm{~mm}=10^{-3} \mathrm{~m}\right)$; $\mathrm{nm}$ : Nanometre (1 $\left.\mathrm{nm}=10^{-9} \mathrm{~m}\right) ; \mathrm{g}$ : Gram ( $\mathrm{g}=10^{-3}$ Kilogram); Gg: Gigagram ( $\left.1 \mathrm{Gg}=10^{6} \mathrm{Kilogram}\right) ; \mathrm{Tg}$ : Teragrams ( $\left.1 \mathrm{Tg}=10^{9} \mathrm{Kilogram}\right)$; $\mathrm{ml}$ : Millilitre $\left(1 \mathrm{ml}=10^{-3} \mathrm{l}\right)$; M: Molar mass of the substance (the mass of one mole of the substance) in $\mathrm{g} / \mathrm{mol}$; $\mathrm{N}$ : Gram equivalent weight of a solute per litre of solution

\section{Acknowledgements}

We would like to acknowledge Dr. Madhanraj K. (Scientist-D, Epidemiology, ICMR-NIREH, Bhopal) for his suggestions and comments intended to further refine the manuscript and the study methodology.

\section{Authors' contributions}

$\Pi$ and YS proposed the conception ideas for the study. TT drafted the manuscript. VD, YS, SA, SN, and RRT edited and proofread the manuscript. All authors read and approved the final manuscript.

\section{Funding}

The study on which this protocol is based was funded by the Indian Council of Medical Research (intramural funding No: 66/12/SAC/NIREH/2018-NCD-II, dt. 04/11/2019). The funder had no role in designing the study, decision to publish, or preparation of the manuscript. Open Access funding provided by Karolinska Institute.

\section{Availability of data and materials}

Not applicable (Data sharing does not apply to this article which describes a study protocol and thus no datasets have been generated or analysed yet).

\section{Ethics approval and consent to participate}

Ethics approval has been obtained from the Institutional (Human) Ethics Committee, National Institute for Research in Environmental Health (No: NIRE H/BPL/IEC/2019-20/1494, dt. 06/01/2020). Written informed consent will be obtained from all participants and the sample forms have been appended (Appendix 3-5 in Supplementary Material).

\section{Consent for publication}

Not applicable as the manuscript is the protocol of a study and no personally identifiable information of the participants has been collected yet.

\section{Competing interests}

The authors declare that they have no competing interests

\section{Author details}

${ }^{1}$ Department of Environmental Health and Epidemiology, ICMR-National Institute for Research in Environmental Health, Bhopal, Madhya Pradesh, India. ${ }^{2}$ Department of Environmental Monitoring And Exposure Assessment (Water and Soil), ICMR-National Institute for Research in Environmental Health, Bhopal, Madhya Pradesh, India. ${ }^{3}$ Department of Global Public Health, Karolinska Institutet, Stockholm, Sweden. ${ }^{4}$ Department of Environmental Monitoring And Exposure Assessment (Air), ICMR-National Institute for Research in Environmental Health, Bhopal, Madhya Pradesh, India. ${ }^{5}$ ICMR-National Institute for Research in Environmental Health, Bhopal, Madhya Pradesh, India. 
Received: 17 October 2020 Accepted: 4 November 2020

Published online: 30 November 2020

\section{References}

1. Manisalidis I, Stavropoulou E, Stavropoulos A, Bezirtzoglou E. Environmental and health impacts of air pollution: a review. Front Public Health. 2020;8:14 Available from: https://pubmed.ncbi.nlm.nih.gov/32154200.

2. Ambient (outdoor) air pollution. World Health Organisation. 2018 [cited 2020 May 4]. Available from: https://www.who.int/en/news-room/factsheets/detail/ambient-(outdoor)-air-quality-and-health.

3. Babatola SS. Global burden of diseases attributable to air pollution. J Public Health Afr. 2018;9(3):813 [cited 2020 Jun 17] Available from: https://www. ncbi.n/m.nih.gov/pmc/articles/PMC6326158/.

4. Lelieveld J, Pozzer A, Pöschl U, Fnais M, Haines A, Münzel T. Loss of life expectancy from air pollution compared to other risk factors: a worldwide perspective. Cardiovasc Res. 2020; [cited 2020 Jun 17]; Available from: https:/academic.oup.com/cardiovascres/advance-article/doi/10.1093/cvr/ cvaa025/5770885.

5. Cohen AJ, Brauer M, Burnett R, Anderson HR, Frostad J, Estep K, et al. Estimates and 25-year trends of the global burden of disease attributable to ambient air pollution: an analysis of data from the Global Burden of Diseases Study 2015. Lancet Lond Engl. 2017;389(10082):1907-18 [cited 2020 Jun 17] Available from: https://www.ncbi.nlm.nih.gov/pmc/articles/ PMC5439030/.

6. Newell K, Kartsonaki C, Lam KBH, Kurmi OP. Cardiorespiratory health effects of particulate ambient air pollution exposure in low-income and middleincome countries: a systematic review and meta-analysis. Lancet Planet Health. 2017;1(9):e368-80 Available from: http://www.sciencedirect.com/ science/article/pii/S2542519617301663.

7. Rodriguez-Villamizar LA, Magico A, Osornio-Vargas A, Rowe BH. The effects of outdoor air pollution on the respiratory health of Canadian children: A systematic review of epidemiological studies. Can Respir J. 2015;22(5):28292 [cited 2020 Jun 17] Available from: https://www.ncbi.n/m.nih.gov/pmc/ articles/PMC4596651/.

8. Yang B-Y, Fan S, Thiering E, Seissler J, Nowak D, Dong G-H, et al. Ambient air pollution and diabetes: A systematic review and meta-analysis. Environ Res. 2020;180:108817 Available from: http://www.sciencedirect.com/science/ article/pii/S0013935119306140.

9. Ghassabian A, Pierotti L, Basterrechea M, Chatzi L, Estarlich M, FernándezSomoano A, et al. Association of Exposure to Ambient Air Pollution With Thyroid Function During Pregnancy. JAMA Netw Open. 2019;2(10):e1912902 [cited 2020 Jun 24] Available from: https://doi.org/10.1001/ jamanetworkopen.2019.12902.

10. Braithwaite I, Zhang S, Kirkbride JB, Osborn DPJ, Hayes JF. Air Pollution (Particulate Matter) Exposure and Associations with Depression, Anxiety, Bipolar, Psychosis and Suicide Risk: A Systematic Review and Meta-Analysis. Environ Health Perspect. 2019;127(12):126002 [cited 2020 Jun 17] Available from: https://www.ncbi.n/m.nih.gov/pmc/articles/PMC6957283/.

11. Peters R, Ee N, Peters J, Booth A, Mudway I, Anstey KJ. Air pollution and dementia: a systematic review. J Alzheimers Dis JAD. 2019;70(s1):S145-63 Available from: https://pubmed.ncbi.nlm.nih.gov/30775976.

12. Kasdagli M, Katsouyanni K, Dimakopoulou K, Samoli E. Air pollution and Parkinson's disease: A systematic review and meta-analysis up to 2018. Environ Epidemiol. 2019;3:193 Available from: https://journals.lww.com/ environepidem/Fulltext/2019/10001/Air_pollution_and_Parkinson_s_ disease_A.587.aspx

13. Giannadaki D, Giannakis E, Pozzer A, Lelieveld J. Estimating health and economic benefits of reductions in air pollution from agriculture. Sci Total Environ. 2018;622-623:1304-16 Available from: http://www.sciencedirect. com/science/article/pii/S0048969717334836.

14. Giannakis E, Kushta J, Giannadaki D, Georgiou GK, Bruggeman A, Lelieveld J. Exploring the economy-wide effects of agriculture on air quality and health: evidence from Europe. Sci Total Environ. 2019;663:889-900 Available from: http://www.sciencedirect.com/science/article/pii/S0048969719304589.

15. Pozzer A, Tsimpidi AP, Karydis VA, de Meij A, Lelieveld J. Impact of agricultural emission reductions on fine-particulate matter and public health. Atmospheric Chem Phys. 2017:17(20):12813-26 [cited 2020 Jun 22] Available from: https://www.atmos-chem-phys.net/17/12813/2017/.

16. Lee CJ, Martin RV, Henze DK, Brauer M, Cohen A, van Donkelaar A Response of global particulate-matter-related mortality to changes in local precursor emissions. Environ Sci Technol. 2015;49(7):4335-44. https://doi. org/10.1021/acs.est.5b00873.

17. Bauer SE, Tsigaridis K, Miller R. Significant atmospheric aerosol pollution caused by world food cultivation. Geophys Res Lett. 2016;43(10):5394-400 [cited 2020 Jun 22] Available from: https://agupubs.onlinelibrary.wiley.com/ doi/abs/10.1002/2016GL068354.

18. Lelieveld J, Evans JS, Fnais M, Giannadaki D, Pozzer A. The contribution of outdoor air pollution sources to premature mortality on a global scale. Nature. 2015;525(7569):367-71 Available from: https://doi.org/10.1038/ nature15371.

19. Aneja VP, Schlesinger WH, Erisman JW. Effects of Agriculture upon the Air Quality and Climate: Research, Policy, and Regulations. Environ Sci Technol. 2009;43(12):4234-40 Available from: https://doi.org/10.1021/es8024403.

20. National Policy for Management of Crop Residue (NPMCR). New Delhi, India: Ministry of Agriculture, Government of India; 2014 Nov [cited 2019 May 29]. Available from: http://agricoop.nic.in/sites/default/files/NPMCR_1.pdf.

21. Zhang X, Lu Y, Wang Q, Qian X. A high-resolution inventory of air pollutant emissions from crop residue burning in China. Atmos Environ. 2019;213: 207-14 Available from: http://www.sciencedirect.com/science/article/pii/ S1352231019303875

22. Cassou E. Agricultural Pollution Field Burning. World Bank Group; [cited 2020 Jun 24]. Available from: http://documents.worldbank.org/curated/en/ 989351521207797690/pdf/124342-repl-WB-Knowledge-Burning.pdf.

23. Shyamsundar P, Springer N, Tallis H, Polasky S, Jat M, Sidhu H, et al. Fields on fire: alternatives to crop residue burning in India. Science. 2019; 365(6453):536-8. https://doi.org/10.1126/science.aaw4085.

24. Andela N, Morton DC, Giglio L, Chen Y, van der Werf GR, Kasibhatla PS, et al A human-driven decline in global burned area. Science. 2017;356(6345): 1356-62 Available from: https://www.ncbi.nlm.nih.gov/pubmed/28663495.

25. Food and Agricultural Organisation of the United Nations. FAOSTAT: Countries by commodity. 2017 [cited 2019 Jun 12]. Available from: http:// www.fao.org/faostat/en/\#rankings/countries_by_commodity.

26. Ravindra K, Singh T, Mor S. Emissions of air pollutants from primary crop residue burning in India and their mitigation strategies for cleaner emissions. J Clean Prod. 2019;208:261-73 Available from: http://www. sciencedirect.com/science/article/pii/S0959652618330397.

27. Agarwal R, Awasthi A, Singh N, Gupta PK, Mittal SK. Effects of exposure to rice-crop residue burning smoke on pulmonary functions and oxygen saturation level of human beings in Patiala (India). Sci Total Environ. 2012; 429:161-6. https://doi.org/10.1016/j.scitotenv.2012.03.074.

28. Saggu GS, Mittal SK, Agarwal R, Beig G. Epidemiological Study on Respiratory Health of School Children of Rural Sites of Malwa Region (India) During Postharvest Stubble Burning Events. MAPAN [Internet]. 2018 Sep 1; 33(3):281-95. Available from: https://doi.org/10.1007/s12647-018-0259-3.

29. Torigoe K, Hasegawa S, Numata O, Yazaki S, Matsunaga M, Boku N, et al. Influence of emission from rice straw burning on bronchial asthma in children. Pediatr Int Off J Jpn Pediatr Soc [Internet]. 2000:42(2):143-50 Available from: http://europepmc.org/abstract/MED/10804729.

30. Agarwal R, Awasthi A, Mittal S, Singh N, Gupta PK. Effects of air pollution on respiratory parameters during the wheat-residue burning in Patiala. J Med Eng Technol. 2010;34(1):23-8. Available from. https://doi.org/10.3109/ 03091900903261258

31. Chakrabarti S, Khan MT, Kishore A, Roy D, Scott SP. Risk of acute respiratory infection from crop burning in India: estimating disease burden and economic welfare from satellite and national health survey data for 250000 persons. Int J Epidemiol. 2019 [cited 2019 Jul 22]; Available from. https://doi. org/10.1093/ije/dyz022.

32. Sarkar C, Kumar V, Sinha V. Massive emissions of carcinogenic benzenoids from paddy residue burning in North India. Curr Sci. 2013:104(12):1703-9 [cited 2019 May 29] Available from: https://www.currentscience.ac.in/ Volumes/104/12/1703.pdf.

33. Gadde B, Bonnet S, Menke C, Garivait S. Air pollutant emissions from rice straw open field burning in India, Thailand and the Philippines. Environ Pollut. 2009;157(5):1554-8 [cited 2019 Aug 6] Available from: http://www. sciencedirect.com/science/article/pii/S0269749109000189.

34. Li C, Hu Y, Zhang F, Chen J, Ma Z, Ye X, et al. Multi-pollutant emissions from the burning of major agricultural residues in China and the related healtheconomic effects. Atmos Chem Phys. 2017:17(8):4957-88 Available from: https://www.atmos-chem-phys.net/17/4957/2017/.

35. Singh $R$, Dhaliwal $H$, Humphreys $E$, Sidhu $H$, Singh $M$, Singh $Y$, et al. Economic assessment of the Happy Seeder for rice-wheat systems in 
Punjab, India. In: AARE2008: Changing climates: Education for sustainable futures. Canberra, Australia: Institute for Land, Water and Society, Charles Sturt University; 2008. [cited 2019 Jul 22]. Available from: https:// researchoutput.csu.edu.au/en/publications/economic-assessment-of-thehappy-seeder-for-rice-wheat-systems-in-2.

36. Kumar $\mathrm{P}$, Kumar $\mathrm{S}$, Joshi L. Alternative uses of crop stubble. In: Kumar $\mathrm{P}$, Kumar S, Joshi $L$, editors. Socioeconomic and environmental implications of agricultural residue burning: a case study of Punjab, India. New Delhi: Springer India; 2015 [cited 2019 Jul 22]. p. 69-89. (SpringerBriefs in environmental science). Available from. https://doi.org/10.1007/978-81-3222014-5_4.

37. Goal $3 .$. Sustainable Development Knowledge Platform [Internet]. [cited 2020 Jun 24]. Available from: https://sustainabledevelopment.un.org/sdg3.

38. Punjab farmers continue to burn crop residue despite pollution alert. The New Indian Express. 2019. [cited 2020 Jun 24]; Available from: https://www. newindianexpress.com/nation/2019/nov/07/punjab-farmers-continue-toburn-crop-residue-despite-pollution-alert-2058412.html.

39. Babu NM. Burning fields: farmers say they are helpless. The Hindu. 2019. [cited 2020 Jun 24]; Available from: https://www.thehindu.com/news/cities/ Delhi/burning-fields-farmers-say-they-are-helpless/article29995283.ece.

40. Madhya Pradesh Population 2011-2020. [cited 2020 Aug 3]. Available from: https://www.census2011.co.in/census/state/madhya+pradesh.html.

41. States Uts - Madhya Pradesh - Know India: National Portal of India. [cited 2020 Aug 3]. Available from: https://knowindia.gov.in/states-uts/madhyapradesh.php.

42. Singh J, Srivastava ShivendraK, Balaji SJ, Singh N. Agricultural Growth Trajectory in Madhya Pradesh: Is It Sustainable? International Journal of Social Scence \& Management Studies [Internet]. 2019 Feb 10;5(1):27-35. Available from: https://papers.ssrn.com/sol3/papers.cfm?abstract_id=3524 810.

43. Tripathi S. Impact of Crop Residue Burning on Climate Change: A Scenario of Madhya Pradesh, India. Res J Recent Sci. 2015;4(IYSC-2015):94-6 [cited 2019 Jun 12] Available from: http://www.isca.me/rjrs/archive/v4/ilYSC-2 015/16.ISCA-IYSC-2015-8EVS-19.pdf.

44. Tehsils in Sehore District, Madhya Pradesh. [cited 2020 Aug 3]. Available from: https://www.census2011.co.in/data/district/312-sehore-madhyapradesh.html.

45. Directorate of Census operation, Pradesh M. Sehore district census Handbook- Village and town-wise Primary Census Abstract. New Delhi: Government of India; 2011. [cited 2020 Feb 6]. (Census of India 2011Madhya Pradesh). Report No.: Series 24-Part XII A. Available from: http:// censusindia.gov.in/2011 census/dchb/2328_PART_B_DCHB_SEHORE.pdf.

46. Cashman SB, Adeky S, Allen AJ, Corburn J, Israel BA, Montaño J, et al. The Power and the Promise: Working With Communities to Analyze Data, Interpret Findings, and Get to Outcomes. Am J Public Health. 2008;98(8): 1407-17 [cited 2020 Aug 3] Available from: http://ajph.aphapublications. org/doi/10.2105/AJPH.2007.113571.

47. Samuel CA, Lightfoot AF, Schaal J, Yongue C, Black K, Ellis K, et al. Establishing new community-based participatory research partnerships using the community-based participatory research Charrette model: lessons from the Cancer health accountability for managing pain and symptoms study. Prog Community Health Partnersh Res Educ Action [Internet]. 2018; 12(1):89-99 Available from: https://pubmed.ncbi.nlm.nih.gov/29606697.

48. Ziegler TB, Coombe CM, Rowe ZE, Clark SJ, Gronlund CJ, Lee M, et al. Shifting from "Community-Placed" to "Community-Based" Research to Advance Health Equity: A Case Study of the Heatwaves, Housing, and Health: Increasing Climate Resiliency in Detroit (HHH) Partnership. Int $J$ Environ Res Public Health. 2019;16(18):3310 Available from: https://pubmed. ncbi.nlm.nih.gov/31505766.

49. Guidelines for the Measurement of Ambient Air Pollutants: Guidelines for Manual Sampling \& Analyses. Delhi: Central Pollution Control Board (CPCB); 2013. p. 145. [cited 2020 Jul 27] (National Ambient Air Quality Series: NAAQ MS/36/2012-13). Available from: http://mahenvis.nic.in/Pdf/Report/report_ epm_NAAQMS\%20.pdf.

50. IS 5182-2 (2001): Methods for Measurement of Air Pollution, Part 2: Sulphur Dioxide (First revision). New Delhi, India: Bureau of Indian Standards; 2001. p. 15. [cited 2020 Jul 27] Available from: https://law.resource.org/pub/in/bis/ S02/is.5182.02.2001.pdf.

51. Jacobs MB, Hochheiser Seymour. Continuous Sampling and Ultramicrodetermination of Nitrogen Dioxide in Air. Anal Chem [Internet]. 1958 Mar 1;30(3):426-8. Available from: https://doi.org/10.1021/ac60135a032.
52. IS 5182-6 (2006): Method for Measurement of Air Pollution, Part 6: Oxides of Nitrogen (First Revision). New Delhi, India: Bureau of Indian Standards; 2006. p. 15. [cited $2020 \mathrm{Jul}$ 27] Available from: https://law.resource.org/pub/ in/bis/S02/is.5182.06.2006.pdf.

53. Awasthi A, Singh N, Mittal S, Gupta PK, Agarwal R. Effects of agriculture crop residue burning on children and young on PFTs in north West India. Sci Total Environ. 2010;408(20):4440-5. https://doi.org/10.1016/j.scitotenv.2010. 06.040 .

54. Kumar R. Respondent Selection Methods in Household Surveys. Jharkhand Jounral Dev Manag Stud. 2014;XIl:5701-8 [cited 2020 Jul 27] Available from: https://www.researchgate.net/publication/267512058_Respondent_ Selection_Methods_in_Household_Surveys.

55. Aggarwal AN, Agarwal R, Dhooria S, Prasad KT, Sehgal IS, Muthu V, et al. Joint Indian Chest Society-National College of Chest Physicians (India) guidelines for spirometry. Lung India Off Organ Indian Chest Soc. 2019; 36(Supplement):S1-35 [cited 2020 Jul 27] Available from: https://www.ncbi. nlm.nih.gov/pubmed/31006703.

56. Mahesh V, Swathi Lekshmi PS, Daliyamol PS, Prakash P, Pawar DA, Kumar A. PRA Techniques in Agriculture: Common Diagraming and Mapping Tools. Indian J Soc Res [Internet]. 2017;58(4):411-22. Available from: http://eprints. cmfri.org.in/12906/. [cited 2020 Jul 13].

57. Bheenaveni R. Participatory Rural Appraisal (PRA): An Analysis of Field Experience in Revanpalli Village of Telangana State, India. IJASSH [Internet]. 2018;0(0). Available from: http://www.ijassh.com/index.php/IJASSH/article/ view/189. [cited 2020 Jul 13].

58. Chatty D, Baas S, Fleig A. Module II: Introducing Participatory Approaches, Methods and Tools. In: Participatory Processes towards Co-Management of Natural Resources in Pastoral Areas of the Middle East: A Training of Trainers Source Book Based on the Principles of Participatory Methods and Approaches [Internet]. Rome and Palmyra: FAO; 2003. Available from: http:// www.fao.org/tempref/docrep/fao/006/ad424e/ad424e00.pdf. [cited 2020 Nov 16].

59. Narayanasamy N. Participatory rural appraisal: principles, Methods and application [Internet]. New Delhi: SAGE Publications India Pvt Ltd; 2020. Available from: http://sk.sagepub.com/books/participatory-rural-appraisal.

60. Guest G, Bunce A, Johnson L. How Many Interviews Are Enough?: An Experiment with Data Saturation and Variability. Field Methods. 2006;18(1):59-82 [cited 2019 Jul 22] Available from: https://doi.org/10.1177/1525822X05279903.

61. Diwan V, Joshi SC, Jehan K, De Costa A. Participation in the state led 'Janani Sahayogi Yojana' public private partnership program to promote facility births in Madhya Pradesh, India: views from private obstetrician partners. BMC Health Serv Res. 2019;19(1):599. [cited 2019 Jul 22] Available from. https://doi.org/10.1186/s12913-019-4409-2.

62. McGrath C, Palmgren PJ, Liljedahl M. Twelve tips for conducting qualitative research interviews. Med Teach. 2019;41(9):1002-6. Available from. https:// doi.org/10.1080/0142159X.2018.1497149.

63. Leung F-H, Savithiri R. Spotlight on focus groups. Can Fam Physician. 2009;55(2): 218-9 [cited 2019 Jul 22] Available from: https:/www.cfp.ca/content/55/2/218.

64. Ritchie J, Spencer L. Chapter 9: Qualitative data analysis for applied policy research. In: Burgess RG, Bryman A, editors. Analyzing qualitative data [Internet]. London ; New York: Routledge; 1994. p.173-94. Available from: https:/www.researchgate.net/profile/Vincenzo_Di_Ciommo/post/ Qualitative_Data_Analysiscan_anyone_point_me_in_the_direction_of_a_ comparative_methodology/attachment/59d61daa79197b80779790f4/AS\%3 A272142535462927\%401441895245006/download/analyzing+qualitative+ data_Bryman+\%26+Burgess.pdf.

65. Pandi-Perumal SR, Akhter S, Zizi F, Jean-Louis G, Ramasubramanian C, Freeman R, et al. Project stakeholder Management in the Clinical Research Environment: how to do it right. Front Psychiatry. 2015;6:71 https:/doi.org/10.3389/fpsyt.2015.00071.

66. McCarty JL, Korontzi S, Justice CO, Loboda T. The spatial and temporal distribution of crop residue burning in the contiguous United States. Sci Total Environ. 2009;407(21):5701-12 Available from: http://www. sciencedirect.com/science/article/pii/S0048969709006342.

67. Yin S, Wang $X$, Zhang $X$, Zhang Z, Xiao Y, Tani H, et al. Exploring the effects of crop residue burning on local haze pollution in Northeast China using ground and satellite data. Atmos Environ. 2019;199:189-201 Available from: http://www.sciencedirect.com/science/article/pii/S1352231018308057.

68. Chawala P, Sandhu HAS. Stubble burn area estimation and its impact on ambient air quality of Patiala \& Ludhiana district, Punjab, India. Heliyon. 2020;6(1):e03095 Available from: http://www.sciencedirect.com/science/ article/pii/S2405844019367544. 
69. Badrinath K, Chand T, Prasad V. Agricultural crop residue burning in the Indo-Gangetic plains- a study using IRS-P6 AWiFS satellite data. Curr Sci. 2006;91(8):1085-9 [cited 2019 May 29] Available from: http://www. environmentportal.in/files/Crop\%20residue.pdf.

70. Gupta S, Agarwal R, Mittal SK. Respiratory health concerns in children at some strategic locations from high PM levels during crop residue burning episodes. Atmos Environ. 2016;137:127-34 [cited 2019 Aug 6] Available from: http://www.sciencedirect.com/science/article/pii/S1352231016303132.

71. Chaba AA. Nation's top wheat contributor tag: How Madhya Pradesh stole Punjab's crown. The Indian Express. 2020 [cited 2020 Jul 10]. Available from: https://indianexpress.com/article/explained/wheat-production-procurementpunjab-madhya-pradesh-6475703/.

72. Jeetendra, Venkatesh S, Pandey K, Niyogi DG, Mukerjee P, Mukerjee P. India's burning issue of crop burning takes a new turn. Down to Earth. [cited 2020 Jun 24]. Available from: https://www.downtoearth.org.in/coverage/ agriculture/river-of-fire-57924.

73. Verma S, Dar JA, Malasiya D, Khare PK, Dayanandan S, Khan ML. A MODISbased spatiotemporal assessment of agricultural residue burning in Madhya Pradesh, India. Ecol Indic. 2019;105:496-504 Available from: http://www. sciencedirect.com/science/article/pii/S1470160X18302954.

74. Sahu L, Sheel V, Pandey K, Yadav R, Saxena P, Gunthe S. Regional biomass burning trends in India: analysis of satellite fire data. J Earth Syst Sci. 2015; 124:1377-87 https://doi.org/10.1007/s12040-015-0616-3.

75. Erenstein $\mathrm{O}$. Cropping systems and crop residue management in the TransGangetic Plains: Issues and challenges for conservation agriculture from village surveys. Agric Syst. 2011;104(1):54-62 [cited 2019 Aug 7] Available from: http://www.sciencedirect.com/science/article/pii/S0308521X10001216.

76. Goswami K, Choudhury HK, Saikia J. Factors influencing farmers' adoption of slash and burn agriculture in north East India. For Policy Econ. 2012;15:14651 Available from: http://www.sciencedirect.com/science/article/pii/S13 89934111001894.

77. Gupta R. Causes of Emissions from Agricultural Residue Burning in NorthWest India: Evaluation of a Technology Policy Response [Internet]. Kathmandu, Nepal: South Asian Network for Development and Environmental Economics (SANDEE); 2012 [cited 2020 Oct 7]. Report No: WP 66-12. Available from: https://ideas.repec.org/p/snd/wpaper/66.html.

78. Sidhu BS, Rupela OP, Beri V, Joshi PK. Sustainability Implications of Burning Rice- and Wheat-Straw in Punjab. Econ Polit Wkly. 1998;33(39):A163-8 [cited 2019 Aug 7] Available from: https://www.jstor.org/stable/4407214.

79. Grover D, Kaur P, Sharma H. Possible reasons and farmers awareness towards crop residue burning: an overview and a case study from Mirzapur village of Kurukshetra district, India. Environ We Int J Sci Technol. 2015;10: 75-85 [cited 2020 Jul 10] Available from: https://www.researchgate.net/ publication/289202446_Possible_reasons_and_farmers_awareness_towards_ crop_residue_burning_an_overview_and_a_case_study_from_Mirzapur_ village_of_Kurukshetra_district_India.

80. Singh B, McDonald AJ, Srivastava AK, Gerard B. Tradeoffs between groundwater conservation and air pollution from agricultural fires in northwest India. Nat Sustain. 2019;2(7):580-3. Available from. https://doi.org/ 10.1038/s41893-019-0304-4

81. Chauhan BS, Mahajan G, Sardana V, Timsina J, Jat ML. Chapter Six Productivity and Sustainability of the Rice-Wheat Cropping System in the Indo-Gangetic Plains of the Indian subcontinent: Problems, Opportunities, and Strategies. In: Sparks DL, editor. Advances in Agronomy: Academic Press; 2012. p. 315-69. Available from: http://www.sciencedirect.com/ science/article/pii/B9780123942784000064

82. Beri V, Sidhu BS, Bahl GS, Bhat AK. Nitrogen and phosphorus transformations as affected by crop residue management practices and their influence on crop yield. Soil Use Manag. 1995;11(2):51-4 [cited 2019 Aug 6] Available from: https://onlinelibrary.wiley.com/doi/abs/10.1111/j.14 75-2743.1995.tb00496.x.

83. Kumar $P$, Singh RK. Selection of sustainable solutions for crop residue burning: an environmental issue in northwestern states of India. Environ Dev Sustain. 2020. https://doi.org/10.1007/s10668-020-00741-x.

84. National Research Council (US) Panel on Race, Ethnicity, and Health in Later Life E. Behavioral Health Interventions: What Works and Why? In: Anderson NB,Bulatao RA, Cohen B, editors. Critical Perspectives on Racial and Ethnic Differences in Health in Late Life [Internet]. Washington (DC): National Academies Press (US); 2004 [cited 2020 Jul 10]. Available from: https://www. ncbi.nlm.nih.gov/books/NBK25527/.
85. Grilli G, Curtis J. Encouraging pro-environmental behaviours: a review of methods and approaches [Internet]. Dublin, Ireland: Economic and Social Research Institute; 2019 Dec [cited 2020 Jul 10]. Report No.: WP No. 645. Available from: https://core.ac.uk/download/pdf/286731419.pdf.

86. Wi A, Chang C-H. Promoting pro-environmental behaviour in a community in Singapore - from raising awareness to behavioural change. Environ Educ Res. 2019;25(7):1019-37. https://doi.org/10.1080/13504622.2018.1528496.

87. Cordova JV. Acceptance in behavior therapy: Understanding the process of change. Behav Anal. 2001;24(2):213-26 [cited 2020 Jul 10] Available from: https://www.ncbi.nlm.nih.gov/pmc/articles/PMC2731500/.

88. Wallerstein N, Oetzel JG, Sanchez-Youngman S, Boursaw B, Dickson E, Kastelic S, et al. Engage for Equity: A Long-Term Study of Community-Based Participatory Research and Community-Engaged Research Practices and Outcomes. Health Educ Behav. 2020;47(3):380-90. [cited 2020 Jul 9] Available from. https://doi.org/10.1177/1090198119897075.

89. Bulthuis SE, Kok MC, Raven J, Dieleman MA. Factors influencing the scale-up of public health interventions in low- and middle-income countries: a qualitative systematic literature review. Health Policy Plan. 2019;35(2):21934. [cited 2020 Oct 7] Available from. https://doi.org/10.1093/heapol/czz140.

90. DeJonckheere M, Lindquist-Grantz R, Toraman S, Haddad K, Vaughn LM. Intersection of Mixed Methods and Community-Based Participatory Research: A Methodological Review. J Mix Methods Res. 2018;13(4):481-502. [cited 2020 Jul 9] Available from. https://doi.org/10.1177/1558689818778469.

91. Goma H, Rahim K, Nangendo G, Riley J, Stein A. Participatory studies for agro-ecosystem evaluation. Agric Ecosyst Environ. 2001;87(2):179-90 Available from: https://www.sciencedirect.com/science/article/abs/pii/S016 7880901002778 .

92. Sandham LA, Chabalala JJ, Spaling HH. Participatory Rural Appraisal Approaches for Public Participation in ElA: Lessons from South Africa. Land. 2019;8(10):150 [cited 2020 Jul 27] Available from: https://www.mdpi.com/2 073-445X/8/10/150.

93. Noble $\mathrm{H}$, Heale R. Triangulation in research, with examples. Evid Based Nurs. 2019;22(3):67 Available from: http://ebn.bmj.com/content/22/3/67.abstract.

\section{Publisher's Note}

Springer Nature remains neutral with regard to jurisdictional claims in published maps and institutional affiliations.

\section{Ready to submit your research? Choose BMC and benefit from:}

- fast, convenient online submission

- thorough peer review by experienced researchers in your field

- rapid publication on acceptance

- support for research data, including large and complex data types

- gold Open Access which fosters wider collaboration and increased citations

- maximum visibility for your research: over $100 \mathrm{M}$ website views per year

At BMC, research is always in progress.

Learn more biomedcentral.com/submission 